\title{
Economic evaluation of a behavioral-graded activity program compared to physical therapy for patients following lumbar disc surgery
}

Citation for published version (APA):

Ostelo, R. W. J. G., Goossens, M., de Vet, H. C. W., \& van den Brandt, P. A. (2004). Economic evaluation of a behavioral-graded activity program compared to physical therapy for patients following lumbar disc surgery. Spine, 29(6), 615-622. https://doi.org/10.1097/01.BRS.0000115130.42394.0B

Document status and date:

Published: 01/01/2004

DOI:

10.1097/01.BRS.0000115130.42394.0B

Document Version:

Publisher's PDF, also known as Version of record

Please check the document version of this publication:

- A submitted manuscript is the version of the article upon submission and before peer-review. There can be important differences between the submitted version and the official published version of record.

People interested in the research are advised to contact the author for the final version of the publication, or visit the DOI to the publisher's website.

- The final author version and the galley proof are versions of the publication after peer review.

- The final published version features the final layout of the paper including the volume, issue and page numbers.

Link to publication

\footnotetext{
General rights rights.

- You may freely distribute the URL identifying the publication in the public portal. please follow below link for the End User Agreement:

www.umlib.nl/taverne-license

Take down policy

If you believe that this document breaches copyright please contact us at:

repository@maastrichtuniversity.nl

providing details and we will investigate your claim.
}

Copyright and moral rights for the publications made accessible in the public portal are retained by the authors and/or other copyright owners and it is a condition of accessing publications that users recognise and abide by the legal requirements associated with these

- Users may download and print one copy of any publication from the public portal for the purpose of private study or research.

- You may not further distribute the material or use it for any profit-making activity or commercial gain

If the publication is distributed under the terms of Article $25 \mathrm{fa}$ of the Dutch Copyright Act, indicated by the "Taverne" license above, 


\title{
Economic Evaluation of a Behavioral-Graded Activity Program Compared to Physical Therapy for Patients Following Lumbar Disc Surgery
}

\author{
Raymond W. J. G. Ostelo, PhD, PT, ${ }^{*} \ddagger$ Mariëlle E. J. B. Goossens, PhD, †S \\ Henrica C. W. de Vet, PhD, $\ddagger$ and Piet A. van den Brandt, PhD*
}

Study Design. An economic evaluation was conducted alongside a randomized controlled trial.

Summary of Background Data. Little is known about the effectiveness of cognitive-behavioral treatment options for patients following lumbar disc surgery. If the knowledge available was supported by an economic evaluation, the information could then be used to make recommendations for the implementation of cognitive-behavioral treatment in the routine of rehabilitation following lumbar disc surgery.

Objective. To examine the cost-effectiveness of a behavioral-graded activity program, which is an operant treatment, compared to usual care as delivered by a physical therapist for patients following first-time lumbar disc surgery.

Methods. For the economic evaluation, a societal viewpoint was applied. The primary outcome measures (measured at the 12-month follow-up) were global perceived effect and functional status. To evaluate the economic consequences of the treatments, direct health care and non-health care costs were considered, as well as indirect costs.

Results. The clinical outcomes showed no relevant differences between behavioral-graded activity $(n=52)$ and $U C(n=53)$. Treatment costs were almost identical in the two intervention groups. The difference in direct health care costs was, although not statistically significant, 264 EURO [95\% Cl: -3-525] higher in behavioralgraded activity than in usual care per patient-year. It was mainly the excess cost of visiting the physiotherapist in the behavioral-graded activity group that accounted for this difference. The difference in direct non-health care costs, although not statistically significant, was 388 EURO [95\% Cl: $-217 ; 992$ ] lower in the usual care group due to unpaid help by friends or family. Consequently, although again not statistically significant, the total direct costs in behavioralgraded activity are 639 EURO [95\% Cl: -91; 1368] higher

From the *Department of Epidemiology and \$Research Institute: Experimental Psychopathology, Maastricht University, Maastricht, †Institute for Rehabilitation Research, Hoensbroek, and $\ddagger V U$ University Medical Center, EMGO Institute, Amsterdam, The Netherlands. The study was funded by grants of the 'Profileringsfonds' of the University Hospital Maastricht (azM) (Grant PF-57 B-96.1.996) and the Foundation 'Annafonds' Leiden, The Netherlands.

Acknowledgment date: February 27, 2003. First revision date: June 2, 2003. Acceptance date: June 6, 2003.

The manuscript submitted does not contain information about medical device(s)/drug(s).

Institutional funds were received to support this work. No benefits in any form have been or will be received from a commercial party related directly or indirectly to the subject of this manuscript.

Address correspondence and reprint requests to Raymond W.J.G. Ostelo, PhD, PT, VU University Medical Center, EMGO Institute, Van der Boechortsstraat 7, Amsterdam 1081 BT, The Netherlands; E-mail: r.ostelo@vumc.nl than in usual care. For the indirect costs, there was a statistically significant difference, behavioral-graded activity being more expensive. The sensitivity analysis showed that these results are fairly robust.

Conclusions. This study concludes that there are no differences between the two treatment conditions on any of the clinical outcome measures but that behavioralgraded activity is associated with higher costs. Consequently, there is no reason for the implementation of behavioral-graded activity as the standard treatment for patients following lumbar disc surgery. [Key words: behavioral treatment, economic evaluation, randomized controlled trial, lumbar disc surgery, low back pain] Spine 2004;29:615-622

In the Netherlands, 10,000 operations are performed each year because of the lumbosacral radicular syndrome, which is based on a herniated lumbar disc. ${ }^{1,2}$ An international comparison of back surgery rates showed considerable differences between countries. ${ }^{3}$ The occurrence of residual complaints after surgery show a wide variety, ranging from $22 \%$ to $45 \%$ of patients reporting residual sciatica after lumbar disc surgery and $30 \%$ to $70 \%$ of patients reporting residual low back pain. ${ }^{4-14}$ Residual complaints mainly consist of pain, motor deficits, and a decreased functional status.

Rehabilitation after lumbar disc surgery is an important tool in order to minimize these complaints. Although many different treatments have been suggested, little is known about the cost-effectiveness of postsurgery rehabilitation. A recently performed systematic review found some evidence for short-term effectiveness of intensive exercise programs that start 4 to 6 weeks postsurgery as compared to mild exercise programs. However, on long-term follow-up, there was no treatment that proved more effective than reference treatments. ${ }^{15}$

Recently, the focus of attention within rehabilitation after lumbar disc surgery has been shifted towards a more biopsychosocial perspective, including cognitivebehavioral interventions. Cognitive-behavioral theory is based on the biopsychosocial model and, following the definition of pain of the International Association for the Study of Pain (IASP), ${ }^{16}$ considers pain to be an emotional experience that can be modulated by cognitive and contextual factors. Based on this model, three cognitivebehavioral treatment methods have been proposed: operant, cognitive, and respondent. ${ }^{17,18}$ Each of these treatment methods focuses on the modification of one of the three response systems that characterize emotional 
Figure 1. Patient flow through study. (mean substitution) = missing values are replaced by group means; UC = usual care; $\mathrm{BGA}=$ behavioral-graded activity.

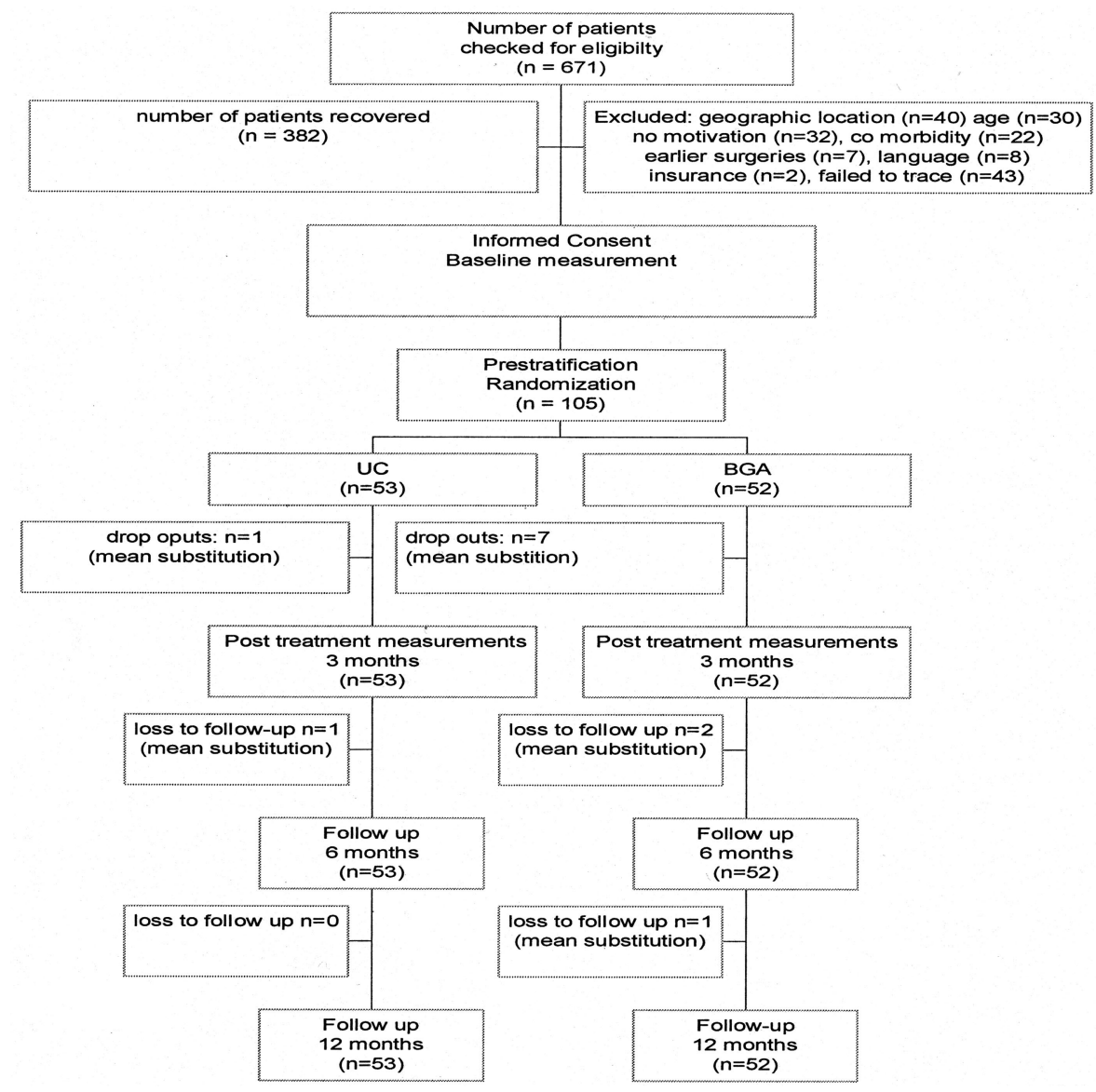

experiences: behavior, cognitions, and physiologic reactivity. So far, these cognitive-behavioral treatments have mainly been described and evaluated within the field of chronic low back pain and not in the rehabilitation after back surgery. A recent systematic review highlighted the effectiveness of cognitive-behavioral interventions, as compared to no treatment, for patients with chronic low back pain. ${ }^{19}$ Despite moderate evidence that cognitivebehavioral treatment is effective, the studies rarely report on economic evaluations undertaken for cognitivebehavioral interventions. ${ }^{20,21}$

Large differences between interventions and studies made it difficult to draw conclusions about the costeffectiveness of most cognitive-behavioral interventions. Nevertheless, it seems that operant and cognitive treatment methods are more cost-effective compared to providing no treatment. ${ }^{22,23}$ However, it remains unclear whether cognitive-behavioral interventions will also be cost-effective for patients following lumbar disc surgery. This paper reports on a randomized controlled trial to assess the cost-effectiveness of an operant treatment compared to usual care as provided by physical therapists in patients following first-time lumbar disc surgery. The design and major clinical findings at the 1-year follow-up are reported elsewhere. ${ }^{24,25}$

\section{Methods}

Study Population. From November 1997 until December 1999 , patients were recruited by 9 neurosurgeons in 4 partici- pating hospitals in the south of the Netherlands. Inclusion criteria were: age between 18 and 65 years; first-time lumbar disc surgery (1 level only); and complaints (e.g., pain) restricting their activities of daily living (ADL) and/or work. Patients were excluded if there were complications during surgery, to be judged by the neurosurgeon based on preset criteria (loss of cerebrospinal fluid, nerve root lesions, and a blood loss exceeding $600 \mathrm{~mL}$ ), in cases of confirmed and relevant underlying diseases that influenced ADL (e.g., stenosis, malignancies, M. Bechterew, M. Scheuerman) or if one of the treatments was contraindicated (e.g., because of respiratory complaints). If patients were eligible and willing to participate, informed consent was signed, and patients were handed an opaque, sealed, and coded envelope prepared by an independent person that contained the allocated treatment. We used block randomization, block size of 4, which was based on a random computergenerated list. The Medical Ethics Committee of the University Hospital Maastricht (The Netherlands) approved the study protocol. Figure 1 presents the flow chart of patients.

\section{Treatments}

Behavioral-Graded Activity. A behavioral-graded activity (BGA) program (18 30-minute sessions in 3 months) is an operant treatment using graded activity and positive reinforcement in order to increase health behaviors and decrease pain behaviors. ${ }^{18,26}$ It is based on time-contingency management as described in more detail by Fordyce and Fordyce $e a^{26,27}$ and applied by Lindström et al. ${ }^{28}$ The term "behavioral-graded activity" for this program emphasizes the behavioral component rather than merely physical training principles and has 
been described extensively elsewhere. ${ }^{24}$ The essence of BGA was to establish an individually tailored exercise program of increasing intensity, based on baseline measurements performed at intake. Physical therapists underwent a 2-day training session, and they received follow-up training during the course of the trial.

Usual Care. The content of usual care (UC; 18 30-minute sessions in 3 months) was determined after extensive interviews with the participating physiotherapists. The main topics of UC could be outlined from the treatment registration forms: all physical therapists instructed their patients to exercise trunk muscles to increase strength and stability. The exercises were aimed at increasing the levels of ADL. Sixty-five percent of the physical therapists explicitly instructed patients how to lift, sit, and stand and how to perform other kinds of ADL. Forty-five percent of the physical therapists used some kind of electrotherapy in at least 3 (or more) sessions to decrease pain and muscle tone. Thirty percent of the physical therapists used some kind of hands-on technique (massage or manipulations) in some of the treatment sessions (ranging from 2 up to 13 sessions) to decrease pain and muscle tonus.

Clinical Outcome Assessment. The main clinical findings at the 1-year follow-up have been reported elsewhere. ${ }^{25}$ In brief, at baseline, gender, type of surgery, duration of hospitalization, and use of analgesics were recorded. Clinical outcome measures (assessed at baseline, posttreatment ( 3 months after randomization), and after 6 and 12 months) included global perceived effect (GPE), the Roland Disability Questionnaire (RDQ), ${ }^{29}$ severity of main complaint, ${ }^{30}$ and severity of back pain. The latter two were scored on a visual analog scale (VAS). Global perceived effect was rated on a 7 -point scale ( $1=$ completely recovered, 7 = worse than ever) that was dichotomized as improved ("completely recovered" and "much improved") versus not improved ("slightly improved," "not changed," "slightly worse," "much worse," "worse than ever"). For general health and social functioning, the subscales of the SF- $36^{31}$ were used.

Costs. The economic evaluation was performed from a societal viewpoint, and the direct health care and nonhealth care costs were considered, as well as the indirect costs. First, relevant categories of resource utilization were identified. Second, the volume of each category was measured. These volumes were measured over a period of 24 weeks ( 2 periods of 12 weeks) and were extrapolated to annual volumes per patient. Finally, these annual volumes were multiplied by the resource costs in order to calculate the costs per patient-year. ${ }^{32}$

Identification of Cost Categories. The direct health care costs included the costs of the allocated treatment; lumbar disc surgery; days of hospitalization; the number of visits to a general practitioner, physical therapist or allied health professional, specialist, or alternative therapist; and prescribed medication. Direct nonhealth care costs included out-of-pocket expenses (i.e., equipment, over-the-counter medication), costs of paid help and help from family or friends, and travel expenses to health care providers. Indirect costs refer to the value of the production lost due to illness-related absence from work or hours of inactivity.

Measurement of Resource Utilization. The participating physical therapists registered the number of treatment sessions attended for BGA and UC. The size of the other direct costs was obtained from the patient-cost diary ${ }^{33}$ in which the patients recorded all medical consumption related to their residual back and/or leg complaints. The calculation of the indirect costs associated with production losses was based on recordings of the number of hours absent from work and the hours lost from activities (unpaid work) at home as listed by the patient in the cost diary. The patients in both groups completed this cost diary prospectively during 2 periods of 3 months within 1 year. For the first period of 3 months, the cost diary was handed out at the posttreatment measurement ( 3 months after randomization). This cost diary was returned at the 6-month follow-up measurement. At the start of the second period ( 9 months after randomization), all patients received another cost diary for the following 3 months, which was returned at the 12-month follow-up measurement. The research assistant checked both cost diaries with regard to completeness for the 6-month and 12month follow-ups, respectively.

Resource Costs. The direct health care and nonhealth care costs were, whenever possible, based on the Dutch guidelines for cost analysis in health care. ${ }^{34}$ For the costs, the 1997 value was used (Dutch guilders were converted into EURO at the rate of 2.2037 guilders to 1 EURO). The costs of various allied health professionals and specialists were based on the tariffs of the Dutch Central Organization for Health Care Charges (COTG). ${ }^{35}$ The professional organizations concerned were asked for tariffs for the various alternative health care therapists. The costs of lumbar disc surgery and of hospitalization were retrieved from the financial department of the participating hospitals. The costs of medication were based on the prices charged by the Royal Dutch Society for Pharmacy. ${ }^{36}$ The prices of over-the-counter medication and the costs of equipment (mattresses, clothing, etc.) were based on the real amounts as reported by the patients in their cost diary. The costs of paid housekeeping were based on the price of professional help. ${ }^{34}$ Unpaid help by family or friends was allocated a value using the shadow price of informal help. ${ }^{34}$ In the analyses for both paid and unpaid labor, the mean income of the Dutch population was used as presented by Statistics Netherlands. ${ }^{37}$ To calculate these costs of paid labor, the Human Capital Approach was used, which estimates the value of the potential production lost during the entire period of absenteeism in 1 patient-year. Table 1 presents the unit prices of the important cost components.

\section{Statistical Analysis}

Clinical Outcome. For this economic evaluation, the clinical outcomes of the 12-month follow-up were used. The analysis was carried out according to the intention-to-treat principle. For the RDQ, the Main Complaint, the severity of back pain, general health, and social functioning, the difference with 12month follow-up values was calculated for each individual; these change scores were used to compare the two treatment groups using the Student $t$ test for statistical significance. For GPE, the difference between groups was analyzed. Group differences and two-tailed 95\% confidence intervals (95\% CI) were calculated for all outcome measures. To adjust for possible baseline differences, a multiple linear regression analysis for continuous outcome measures was used, with the change scores as dependent variable, treatment as independent variable, and baseline scores of the prognostic variables (and the particular outcome measure, if appropriate) as covariables. 
Table 1. Prices Used in the Economic Evaluation (in EURO)

\begin{tabular}{|c|c|}
\hline Costs & EURO \\
\hline \multicolumn{2}{|l|}{ Direct health care costs } \\
\hline General practitioner (per contact) ${ }^{34}$ & 16.62 \\
\hline Physiotherapist (per contact) ${ }^{34}$ & 18.18 \\
\hline Manual therapist (per contact) ${ }^{34}$ & 24.55 \\
\hline Cesar/Mensendieck exercise therapist (per contact) ${ }^{34}$ & 17.73 \\
\hline Hospitalization (per day)* & 236.36 \\
\hline Lumbar disc surgery* & 424.55 \\
\hline Specialist (per contact) ${ }^{35}$ & Variable \\
\hline Alternative health care (per contact) $\dagger$ & Variable \\
\hline \multicolumn{2}{|l|}{ Direct non-health care costs } \\
\hline Paid housekeeping help (per hr) ${ }^{34}$ & 8.55 \\
\hline Unpaid help from family/friends $(\mathrm{per} \mathrm{hr})^{34}$ & 7.95 \\
\hline Travel expenses $(\text { per } \mathrm{km})^{34}$ & 0.11 \\
\hline Expenses for health activities $\ddagger$ & Variable \\
\hline Costs for equipment $\ddagger$ & Variable \\
\hline \multicolumn{2}{|l|}{ Indirect costs } \\
\hline Absenteeism paid labor $(\text { per } \mathrm{hr})^{37}$ & 15.12 \\
\hline Absenteeism unpaid labor (per $\mathrm{hr})^{37}$ & 15.12 \\
\hline
\end{tabular}

The adjusted results hardly changed the outcome, and therefore we present only the unadjusted results.

Costs. The mean costs of the allocated treatment group were used to substitute missing values. If patients forgot to bring their cost diary with them they had to fill one out, retrospectively, during the follow-up measurement. The differences between the two groups for health care utilization and use of other health care services were compared using the MannWhitney test. For comparing the costs between the two groups, the standard approach of the Student $t$ test was used because for this comparison the arithmetic mean costs are considered to be most informative. ${ }^{38}$ Furthermore, $95 \%$ CIs were calculated.

Sensitivity Analyses. The analysis of the costs is based on several assumptions. The impact on the results of changing these assumptions can be assessed in sensitivity analyses. If changes in the results due to different assumptions are minor, the results can be treated with greater confidence. If the sensitivity analysis produces substantial changes in the results, then greater caution is necessary when interpreting the data. Three alternative costs analyses will be performed.

The cost analysis is based on the assumption that for comparing the treatment groups with regard to the costs the arithmetic mean is most informative, despite the fact that data are skewed and therefore we used the standard approach of the Student $t$ test. ${ }^{38}$ In a sensitivity analysis, we used the MannWhitney test in order to account for the skewing of the data.

Reporting the volume of unpaid help from friends or family can be imprecise because patients might hold different views with regard to what exactly is understood by this type of help. Furthermore, the exact number of hours may be difficult to estimate because this help often consists of a series of small tasks, sometimes incorporated in a social visit. Therefore, we analyzed the influence of this cost category by excluding it.

Finally, the measurement of indirect cost was based on the Human Capital Approach, which estimates the value of the potential production lost during the entire period of absenteeism in 1 patient-year. This method is likely to overestimate the
Table 2. Baseline Comparison of Patient Characteristics and Clinical Outcome Measures

\begin{tabular}{lll}
\hline Clinical Outcome Measure & UC (n = 53) & BGA ( $=52)$ \\
\hline Age (yrs) & $43.7(8.8)$ & $42.8(8.8)$ \\
Women (\%) & 35.8 & 50.0 \\
Duration of symptoms before surgery & 17 & 13 \\
$\quad$ 3 mos (\%) & 83 & 87 \\
$\quad$ 3 mos (\%) & 70 & 78 \\
Type of surgery: standard discectomy (\%) & $7.7(2.7)$ & $7.0(1.3)$ \\
Duration of hospitalization (days) & 34 & 38 \\
Pain medication (\%) & $13.5(4.5)$ & $14.5(3.7)$ \\
Roland Disability Questionnaire (0-24) & $67.4(15.4)$ & $71.1(16.5)$ \\
Main Complaint (0-100) & $46.7(27.3)$ & $43.4(30.0)$ \\
Severity of pain in back (0-100) & $65.6(20.0)$ & $68.2(18.4)$ \\
General Health (subscale SF-36) & $59.4(25.3)$ & $56.7(26.6)$ \\
Social Functioning (subscale SF-36) & & \\
\hline Numbers are means with standard deviations in parentheses. & \\
UC = usual care; BGA = behavior-graded activity. &
\end{tabular}

actual loss, because in reality others may replace missing workers, or the absentee may make up the lost production once he or she returns to work. To approximate the actual production loss, it is more realistic to assume that losses occur only during the time needed to replace the sick worker, or to reorganize the production process. This is called the friction time. In another sensitivity analysis, we estimated the value of the production loss assuming that no production is lost after this friction time. Koopmanschap and Rutten, ${ }^{39}$ who developed the Friction Costs Approach, estimated the approximate friction time to be 3 months.

\section{Results}

\section{Patients}

From November 1997 until December 1999, 671 patients were screened for eligibility in 4 participating hospitals in the South of the Netherlands. Figure 1 presents the patient flow. In total, 105 patients $(16 \%)$ were eligible and signed informed consent. Table 2 presents the baseline characteristics and the baseline values for the clinical outcome measures used in this cost-effectiveness analysis. Overall, there were no relevant differences between groups at baseline.

\section{Clinical Outcomes}

After 12 months, the proportion of patients who recovered (GPE) in the BGA and UC groups was $75 \%$ and $73 \%$, respectively. The difference of $2 \%(95 \%$ CI: -19.5-15.7) was not statistically significant, nor clinically relevant. For the RDQ, the severity of back pain, and the Main Complaint, no differences could be observed. For general health and social functioning, again no differences were observed between the two groups. Table 3 presents the effects of the clinical outcome measures.

\section{Costs}

Response of Cost Dairies. In the BGA group, $63.5 \%$ completed the cost diaries prospectively and turned them in at the follow-up measurements versus $86.8 \%$ in the UC group. In BGA and UC, 9 patients and 5 patients, respec- 
Table 3. Improvement in Clinical Outcome Measures and Differences in Improvement Between the Treatment Groups After 12 Months

\begin{tabular}{lccc}
\hline Outcome Measures & $\mathrm{BGA}^{*}(\mathrm{n}=52)$ & $\mathrm{UC}^{*}(\mathrm{n}=53)$ & Difference $\dagger$ \\
\hline Recovered (\%) & \multicolumn{1}{c}{75} & 73 & $2.0(-19.5 ; 15.7)$ \\
Roland Disability & $7.0(5.5)$ & $7.0(5.3)$ & $0.0(-2.1 ; 2.1)$ \\
$\quad$ Questionnaire & & & \\
Main Complaint (0-100) & $50.3(27.4)$ & $44.3(30.6)$ & $6.0(-5.5 ; 17.3)$ \\
Severity of back pain & $17.6(32.5)$ & $22.4(33.6)$ & $-4.8(-17.5 ; 7.9)$ \\
$\quad(0-100)$ & & & \\
General Health $\ddagger$ & $3.0(16.4)$ & $5.2(16.6)$ & $-2.2(-8.6 ; 4.2)$ \\
Social Functioning $\ddagger$ & $28.4(27.7)$ & $24.1(25.1)$ & $4.3(-14.5 ; 5.9)$ \\
\hline
\end{tabular}

* Presented are the improvements from baseline, either percentage or mean (SD).

† Presented are the differences (behavioral-graded activity minus usual care) in recovery differences of mean improvement from baseline $195 \%$ confidence interval).

‡ Subscale SF-36.

$\mathrm{BGA}=$ behavioral-graded activity; $\mathrm{UC}=$ usual care

tively, did not keep track of the costs prospectively and had to complete the cost diaries in retrospect during the follow-up measurements. In BGA and UC, 10 patients and 2 patients, respectively, were lost to follow-up 12 months after randomization, and mean values of their treatment groups were used for substitution.

Direct Health Care Costs. Table 4 shows the volumes per patient-year for the various categories of health care utilization and other services. The number of treatment sessions attended is comparable for both groups. Patients in both groups hardly visited the general practitioner or medical specialist, and the difference is not statistically significant. In the BGA group, 20 patients $(38.5 \%)$ visited an allied health professional; in 18 cases this was a physical therapist. In UC, 13 patients visited allied health professionals, all of whom were physical therapists. The number of visits to allied health professionals is statisti-

Table 4. Mean (SD) Utilization of Health Care and Other Services per Patient-year by Cost Category and Treatment Group

\begin{tabular}{|c|c|c|c|}
\hline $\begin{array}{l}\text { Type of Utilization [Type of } \\
\text { Measurement] }\end{array}$ & $\begin{array}{c}\text { BGA } \\
\text { Mean (SD) } \\
(\mathrm{n}=52)\end{array}$ & $\begin{array}{c}\text { UC } \\
\text { Mean (SD) } \\
(\mathrm{n}=53)\end{array}$ & $P$ Value* \\
\hline $\begin{array}{l}\text { Allocated treatment [no. of } \\
\text { sessions] }\end{array}$ & $15.3(3.8)$ & $16.0(3.3)$ & 0.088 \\
\hline General practice [no. of visits] & $2.1(3$. & $1.6(3$ & 0.246 \\
\hline $\begin{array}{l}\text { Allied health professions [no. } \\
\text { of treatment sessions] } \dagger\end{array}$ & $15.7(22.1)$ & $6.7(1$ & 0.005 \\
\hline $\begin{array}{l}\text { Medical specialist care [no. of } \\
\text { visits] }\end{array}$ & $2.8(4.5)$ & $3.0(7.4)$ & 0.153 \\
\hline $\begin{array}{l}\text { Alternative health care [no. of } \\
\text { visits] }\end{array}$ & $0.5(1.7)$ & $0.1(0.6)$ & 0.001 \\
\hline Surgery [no.] & $0.1(0.3)$ & 0.0 & 0.003 \\
\hline $\begin{array}{l}\text { Unpaid help from friends/family } \\
\text { [hrs] }\end{array}$ & $58.4(127.3)$ & $16.6(54.7)$ & 0.007 \\
\hline Paid housekeeping [hrs] & $23.8(58.5)$ & $16.1(54.0)$ & 0.016 \\
\hline \multicolumn{4}{|c|}{$\begin{array}{l}\text { Bold type indicates statistical significant difference between groups at alpha = } \\
0.05 \text {. } \\
\text { * Mann-Whitney test. } \\
\text { † Allied health professions are physical therapy, manual therapy, and Cesar/ } \\
\text { Mensendieck exercise therapy. }\end{array}$} \\
\hline
\end{tabular}

Table 5. Difference in Mean Total Costs (SD) per Patient-year During the Complete Follow-up Period of 12 Months (in EURO)

\begin{tabular}{lccc}
\hline & $\begin{array}{c}\text { BGA } \\
\text { Mean (SD) } \\
(\mathrm{n}=52)\end{array}$ & $\begin{array}{c}\text { UC } \\
(\mathrm{n}=53)\end{array}$ & $\begin{array}{c}\text { BGA-UC } \\
\text { Costs }\end{array}$ \\
\hline Treatment costs & $278(63)$ & $291(60)$ & $-13(-37 ; 11)$ \\
Direct health care costs & $565(822)$ & $301(489)$ & $264(-3 ; 525)$ \\
Direct non-health care costs & $1135(1486)$ & $747(1633)$ & $388(-217 ; 992)$ \\
Total direct costs & $1978(1894)$ & $1339(1873)$ & $639(-91 ; 1368)$ \\
\hline
\end{tabular}

Mean $=$ mean difference in total costs between treatment groups

$95 \% \mathrm{Cl}=95 \%$ confidence interval; $\mathrm{BGA}=$ behavioral-graded activity; $\mathrm{UC}=$ usual care.

cally significant higher in BGA. There were also statistically significantly more visits to alternative therapists by BGA patients. There was one repeated surgery in BGA but no repeated surgery in UC. There is a statistically significant difference to the disadvantage of the BGA with regard to unpaid help and paid housekeeping.

Converting these annual volumes of health care use and other services into mean total costs per patient-year, it appeared that there was only a small difference in treatment costs of 13 EURO (95\% CI: - 37; 11) in favor of BGA (Table 5). The difference in direct health care costs, although not statistically significant, was 264 EURO (95\% CI: $-3 ; 525$ ) higher per patient-year in BGA than in UC. It was mainly the excess cost of visiting the physiotherapist in the BGA group that accounted for this difference. The direct nonhealth care costs, although not statistically significant, were 388 EURO (95\% CI: - 217; 992) higher in BGA. Mainly, the costs for unpaid help from friends or family accounted for this difference. Consequently, although again not statistically significant, the total direct costs in BGA are 639 EURO (95\% CI: -91; 1368) higher in BGA than in UC.

Indirect Costs. During the 12-month follow-up, the average duration of absence from work because of complaints was 381.3 hours per patient-year (or 0.92 days per week) for BGA and 155.0 hours for UC (0.37 days per week). The associated costs amounted to 5774 EURO (SD: 8880) for BGA and 2347 EURO (SD: 6064) for UC. The 3427 EURO (95\% CI: 489-6365) difference between the 2 groups is statistically significant. Also, the mean duration of absenteeism from unpaid labor per patient-year was higher in BGA. The associated costs for unpaid labor amounted to 1421 EURO (SD 2804) for BGA and 407 EURO (SD 1386) for UC. The 1014 EURO (95\% CI: 160-1868) difference between the 2 groups per patient-year is statistically significant.

\section{Sensitivity Analysis}

Parametric Versus Nonparametric Testing. Using the Mann-Whitney test in order to account for the skewness of the data, the difference between treatment cost was still not statistically significantly different. But the differences in direct and nondirect health care costs now 
reached statistical significance, meaning that BGA generates more costs than UC. Also, the difference in total direct costs, to the disadvantage of BGA, is statistically significant. The differences in costs of absenteeism from paid and unpaid labor, to the disadvantage of BGA, are statistically significant, using the Mann-Whitney test.

Excluding Unpaid Help From Friends or Family. The difference between BGA and UC, on excluding unpaid help from friends or family, was reduced to 28 EURO $195 \%$ CI: $-501 ; 445)$, but the cost was still higher for BGA. The difference in total direct costs was reduced to 280 EURO $(95 \%$ CI: $-868 ; 310)$. But again, this difference, although not statistically significant, was to the disadvantage of BGA.

Human Capital Approach Versus Friction Cost Approach. Using the main assumptions of the Friction Cost Approach instead of the Human Capital Approach reduced the indirect costs in both groups. During the 12 months of follow-up, 3 BGA patients and only 1 UC patient were absent from paid labor for more than 3 months. Consequently, the costs of absenteeism from paid labor was reduced more in BGA than in UC, yielding a difference of 2555 EURO (95\% CI: $395 ; 4713)$ as compared to a difference of 3427 EURO (95\% CI: 489; 6365), using the Human Capital Approach. However, the costs in BGA associated with absenteeism from paid labor were still statistically significantly higher.

In general, no matter what changes in cost assumptions were made, the changes in the results were minor, thereby strongly supporting the conclusion that BGA is associated with higher costs.

\section{- Discussion}

In a randomized controlled trial, the cost-effectiveness of the BGA program was compared to UC in patients following first-time lumbar disc surgery. After 12 months, there were no statistically significant or clinically relevant differences on any of the clinical outcome measures. The treatment costs were comparable for both groups. However, comparing the total direct costs, it appeared that there was a difference, although not statistically significant, of 639 EURO $(95 \%$ CI: -91; 1368) to the disadvantage of BGA. The indirect costs were also higher in BGA as compared to UC per patient-year. This difference was statistically significant.

The utilization of health care and other services (Table 4) reveal that, although not all categories show statistically significant differences, there was a clear pattern. All categories reflect a higher health care utilization in the BGA group. Especially the number of visits to physical therapist showed a distinct difference, as well as costs for unpaid help from friends or family. This observation was not in line with the expectations at the beginning of this trial. The overall goal of the operant treatment is to teach the patient that it is safe to increase activity level and to provide them with tools in order to improve their ability to be self-supporting. Furthermore, it was hypothesized that BGA would alter two important psychological mediators: fear of movement and catastrophizing. Because these mediators would be altered in a positive direction and the self-supportiveness would be increased, visits to physical therapists were expected to be lower rather than higher in the BGA group. One possible explanation might be that these theories derived from the field of chronic low back pain might not apply to patients following lumbar disc surgery. This explanation is supported by the results for the psychological mediators. Fear of movement and catastrophizing seem to be unaffected, on average, by either treatment. ${ }^{25}$

Another explanation might be that patients held different expectations with regard to the BGA treatment, such that they expected more passive methods for reduction of pain and more pain-guided management in general. Therefore, physiotherapists might not have succeeded in dispelling fear and insecurities. Consequently, patients being still more insecure with regard to their own abilities might have been more inclined to seek help from another physiotherapist in the subsequent year.

Considering the costs of absence from paid labor, it appeared that BGA generated more costs than UC, in both the Human Capital as well as the Friction Cost Approach. However, some remarks have to be made. First, return to work is possibly also an outcome that results from the surgery that patients underwent 6 weeks before inclusion in our trial. The natural course of recovery after surgery has probably influenced return to work to a great extent. Second, return to work was not a specific treatment goal for either BGA or UC. The main goal of these types of treatments is to improve functional status. If patients are absent from work following lumbar disc surgery and if return to work is of paramount importance to them, more specific reintegration approaches focusing primarily on early resumption of professional activities are probably needed in order to improve the chance of return to work. ${ }^{40}$ In summary, despite the consistent findings in the analysis, the results with regard to absence from paid labor have to be interpreted cautiously.

The costs of absenteeism from unpaid labor and days of inactivity at home were included merely to get an impression of how high they were; patients who do not participate in paid labor were included (e.g., housewives, [early] retired persons). In retrospect, the definition of this variable was too imprecise, and therefore, patients used different criteria to determine the number of hours for this variable. For future research, it is important to describe this variable more precisely.

With regard to assumptions made in this economic evaluation, some comments are worth mentioning. Because in our study we adopted the societal perspective, we did not restrict the cost analysis to treatment costs and health care utilization. We also included other relevant categories, including costs borne by the patient and family, such as over-the-counter medication, equipment, paid and unpaid help from friends and family, and indi- 
rect costs. Because of the patients' decisive role in reporting, the identification and measurement of these nonmedical costs is somewhat arbitrary because they cannot be checked elsewhere. However, the sensitivity analysis showed that in general, the various assumptions did not alter the results substantially.

In our study, patients had to keep a diary for 2 periods of 3 months. The main reason for shortening the period during which cost diaries were kept was that this minimized the burden for patients. Keeping the diary for a whole year would probably have resulted in more precise estimates of the costs. However, a study by Goossens et $a l^{33}$ on fibromyalgia and chronic low back pain showed that keeping cost diaries for a period of 3 months was representative of keeping the diary for the whole year. Therefore, we assume that the costs recorded in our trial are representative of the costs for the whole year, and furthermore, we even used 2 periods of 3 months.

In this economic evaluation, we performed the analysis on the raw costs as advocated by Thompson and Barber, ${ }^{38}$ despite the usual skewness in their distribution. There is still no consensus about the most valid and reliable statistical method for comparing costs in pragmatic trials. Thompson and $\mathrm{Barber}^{38}$ argue that the arithmetic mean is needed for health care policy decisions and that using standard nonparametric methods may provide misleading conclusions. However, using a nonparametric method (Mann Whitney $U$ ) did not change our results substantially.

In summary, we found no differences in any of the clinical outcome measures. The costs associated with BGA were, however, higher as compared to UC. Therefore, we conclude that, based on this economic evaluation, there is no need to implement the BGA program as delivered in the current study as the standard treatment for patients following lumbar disc surgery.

\section{- Key Points}

- An economic evaluation was conducted, alongside a randomized controlled trial, in which costeffectiveness of a behavioral-graded activity program was compared to usual care, as delivered by a physical therapist, in patients following first-time lumbar disc surgery.

- It was concluded that there are no differences between the two treatment conditions on any of the clinical outcome measures but that behavioralgraded activity is associated with higher costs.

- Consequently, there is no reason for the implementation of behavioral-graded activity as the standard treatment for patients following lumbar disc surgery.

\section{Acknowledgments}

We gratefully acknowledge Cobie Martens for her data management support.

\section{References}

1. Management of the Lumbosacral Radicular Syndrome (Sciatica). The Hague: Health Council of the Netherlands; 1999.

2. Slebus FG, Van Der Maas PJ, Braakman R, et al. De Effectiviteit van Beeldvormende Diagnostiek en Chirurgie bij de Lumbale Hernia Nuclei Pulposi. Rotterdam: Rapport aan het Ministerie van WVC; 1989.

3. Cherkin DC, Deyo RA, Loeser JD, et al. An international comparison of back surgery rates. Spine 1994;19:1201-6.

4. Barrios C, Ahmed M, Arrotegui JI, et al. Clinical factors predicting outcome after surgery for herniated lumbar disc: an epidemiological multivariate analysis. J Spinal Disord 1990;3:205-9.

5. Dvorak J, Valach L, Fuhrimann P, et al. The outcome of surgery for lumbar disc herniation. II. A 4-17 years' follow-up with emphasis on psychosocial aspects. Spine 1988;13:1423-7.

6. Hurme M, Alaranta H. Factors predicting the result of surgery for lumbar intervertebral disc herniation. Spine 1987;12:933-8.

7. Korres DS, Loupassis G, Stamos K. Results of lumbar discectomy: a study using 15 different evaluation methods. Eur Spine J 1992;1:20-4.

8. Manniche C, Asmussen KH, Vinterberg H, et al. Analysis of preoperative prognostic factors in first-time surgery for lumbar disc herniation, including Finneson's and modified Spengler's score systems. Dan Med Bull 1994;41: 110-5.

9. Manniche C, Asmussen KH, Vinterberg H, et al. Back pain, sciatica and disability following first-time conventional hemilaminectomy for lumbar disc herniation. Use of "Low Back Pain Rating Scale" as a postal questionnaire. Dan Med Bull 1994;41:103-6.

10. Pappas CT, Harrington T, Sonntag VK. Outcome analysis in 654 surgically treated lumbar disc herniations. Neurosurgery 1992;30:862-6.

11. Smulders WLM, van Loon G. Nabehandeling na lumbale discectomie of chemonucleolyse. Een "out-patient" enquête. Fysiopraxis 1993;2:4-6.

12. Spangfort EV. The lumbar disc herniation. A computer-aided analysis of 2,504 operations. Acta Orthop Scand Suppl 1972;95:1421-95.

13. Weber H. Lumbar disc herniation. A controlled, prospective study with ten years of observation. Spine 1983;8:131-40.

14. Yorimitsu E, Chiba K, Toyama Y, et al. Long-term outcomes of standard discectomy for lumbar disc herniation: a follow-up study of more than 10 years. Spine 2001;26:652-7.

15. Ostelo RW, de Vet HC, Waddell G, et al. Rehabilitation after lumbar disc surgery. A systematic review within the framework of the Cochrane Bach Review Group. Spine 2003;28:209-18.

16. International Association for the Study of Pain SoT. Classification of chronic pain syndromes and definitions of pain terms. Pain 1986;(suppl 3):s1-s225.

17. Turk DCFH. Etiological theories and treatments for chronic back pain. II. Psychological models and interventions. Pain 1984;19:209-33.

18. Vlaeyen JW, Haazen IW, Schuerman JA, et al. Behavioural rehabilitation of chronic low back pain: comparison of an operant treatment, an operantcognitive treatment and an operant-respondent treatment. Br J Clin Psychol 1995;34:95-118.

19. van Tulder MW, Ostelo RWJG, Vlaeyen JWS, et al. Behavioral treatment for chronic low back pain: a systematic review within the framework of the Cochrane Back Review Group. Spine 2001;26:270-81.

20. Goossens MEJB, Evers SMAA. Cost-effectiveness of treatment of back pain. In: Nachemson A, Jonsson E, eds. Evidence Based Treatment for Back Pain. Philadelphia, PA: Lippincott, Williams \& Wilkins; 2000.

21. Goossens ME, Evers SM. Economic evaluation in back pain interventions. $J$ Occup Rehabil 1997;7:15-32.

22. Goossens ME, Rutten van Molken MP, Leidl RM, et al. Cognitiveeducational treatment of fibromyalgia: a randomized clinical trial. II. Economic evaluation. J Rheumatol 1996;23:1246-54.

23. Goossens ME, Rutten-van Mulken MP, Kole-Snijders AM. Health economic assessment of behavioral rehabilitation in chronic low back pain: a randomized clinical trial. Health Econ 1998;7:39-51.

24. Ostelo RW, Köke AJ, Beurskens AJ, et al. Behavioral-graded activity compared with usual care after first-time disk surgery: considerations of the design of a randomized clinical trial. J Manipulative Physiol Ther 2000;23: 312-9.

25. Ostelo RW, Vet de HC, Vlaeyen JW, et al. Behavioral graded activity after first-time lumbar disc surgery. One year results of a randomized controlled trial. Spine 2003;28:1757-65.

26. Fordyce WE. Behavioral Methods for Chronic Pain and Illness. St. Louis, MO: Mosby; 1976.

27. Fordyce WE, Fowler RS Jr, Lehmann JF, et al. Operant conditioning in the treatment of chronic pain. Arch Phys Med Rehabil 1973;54:399-408.

28. Lindström I, Öhlund C, Eek C, et al. The effect of graded activity on patients 
with subacute low back pain: a randomized prospective clinical study an operant-conditioning behavioral approach. Phys Ther 1992;72:279-93.

29. Roland M, Morris R. A study of the natural history of back pain. Part I: development of a reliable and sensitive measure of disability in low-back pain. Spine 1983;8:141-4.

30. Beurskens AJ, de Vet HC, Köke AJ, et al. A patient-specific approach for measuring functional status in low back pain. J Manipulative Physiol Ther 1999;22:144-8.

31. Ware JE Jr, Sherbourne CD. The MOS 36-item short-form health survey (SF-36). I. Conceptual framework and item selection. Med Care 1992;30: 473-83.

32. Rutten van Mölken MP, van Doorslaer EK, van Vliet RC. Statistical analysis of cost outcomes in a randomized controlled trial. Health Econ 1994;3:333-45.

33. Goossens ME, Rutten van Molken MP, Vlaeyen JW, et al. The cost diary: a method to measure direct and indirect costs in cost-effectiveness research. J Clin Epidemiol 2000;53:688-95.

34. Oostenbrink JB, Koopmanschap MA, Rutten FFH. Handbook for Cost
Studies, Methods and Guidelines for Economic Evaluation in Health Care [in Dutch]. Amstelveen: Health Care Insurance Council; 2000.

35. Centraal Orgaan Tarieven Gezundheidszorg (COTG). Tarieven voor Medisch Specialisten, Exclusief Psychiaters. Bijlage bij Tariefbeschikking 5600-1900-97 dd. 21 Oktober 1996. Utrecht: Centraal orgaan Tarieven Gezondheidszorg; 1996.

36. Report. T. Z-index. The Hague; 2000.

37. Centraal Bureau vd Statistiek (CBS). Wergelegenheid, Arbeidsduur en Lonen van Werknemers, Vanaf 1995. Heerlen Voorburg: Statistics Netherlands; 1995.

38. Thompson SG, Barber JA. How should cost data in pragmatic randomized trials be analyzed? Br Med J 2000;320:1197-200.

39. Koopmanschap MA, Rutten FF. Indirect costs in economic studies: confronting the confusion. Pharmaco Econ 1993;4:446-54.

40. Donceel P, Du Bois M, Lahaye D. Return to work after surgery for lumbar disc herniation. A rehabilitation-oriented approach in insurance medicine. Spine 1999;24:872-6. 